\title{
BMJ Open Correlations of skin fold thickness and validation of prediction equations using DEXA as the gold standard for estimation of body fat composition in Pakistani children
}

\author{
Zainab Hussain, ${ }^{1}$ Tazeen Jafar, ${ }^{2}$ Maseeh uz Zaman, ${ }^{1}$ Riffat Parveen, ${ }^{1}$ \\ Farzan Saeed ${ }^{2}$
}

To cite: Hussain Z, Jafar T,

Zaman M uz, et al.

Correlations of skin fold thickness

and validation of prediction equations using DEXA as the gold standard

for estimation of body fat composition in Pakistani children. BMJ Open 2014;4: e004194. doi:10.1136/ bmjopen-2013-004194

- Prepublication history for this paper is available online. To view these files please visit the journal online (http://dx.doi.org/10.1136/ bmjopen-2013-004194)

Received 8 October 2013 Revised 24 February 2014 Accepted 17 March 2014

\section{(a) CrossMark}

${ }^{1}$ Department of Radiology, The Aga Khan University Hospital (AKUH), Karachi, Pakistan

${ }^{2}$ Department of Community Health Sciences (CHS), The Aga Khan University Hospital (AKUH), Karachi, Pakistan

Correspondence to Dr Maseeh uz Zaman; maseeh.uzzaman@aku.edu

\section{ABSTRACT}

Objective: To determine the correlation between dual energy X-ray absorptiometry (DEXA) and skin fold thickness (SKF) equations for estimation of body fat (BF) composition in secondary school children and validation of prediction equations by Slaughter, Goran and Dezenberg.

Design: Cross sectional analytical study.

Setting: Joint Commission for International Accredited (JCIA) tertiary care hospital of Karachi, Pakistan from January 2010 to May 2010.

Participants: The study was approved by the Hospital's ethical review committee. Written and verbal consents were obtained from principals of two schools and parents of 99 children (mean age of $14 \pm 1.89$ years; min-max 9-19 years; 54 men and 45 women) accrued in study. DEXA scan was acquired and SKF was measured at angle of the scapula, iliac crest and mid-arm for bicep and tricep skin folds using Holtain Callipers. Correlations were established between estimated fat mass (FM) and per cent BF (\%BF) calculated by DEXA and those predicted by prediction equations. On obtaining significant correlation of $>0.5$, overall accuracy, precision and bias was calculated.

Results: There was an overall increased adiposity in females with $\mathrm{FM}$ of $3.57 \mathrm{~kg}$ and $\% \mathrm{BF} 6.2 \%$ higher than male counterparts $(p<0.05)$. Slaughter equation predicted \%BF accurately with overall high accuracy, minimal bias and with good precision with DEXA. Dezenberg and Goran equations had significant bias in prediction of FM which was statistically significant with low level of accuracy of the Goran equation.

Conclusions: We conclude that Slaughter equation for estimating \%BF showed reasonable validation with DEXA. Nevertheless further studies with consideration for maturity and ethnicity are warranted for better results. However, for estimation of FM, previously formulated equations by Goran and Dezenberg showed significant difference in our population. We do recommend further studies for developing and validation of skin fold equations specific to Pakistani paediatric population.

\section{Strength and limitations of this study}

This is the first well-designed and conducted study from a Joint Commission for International Accredited (JCIA) accredited tertiary care hospital (Aga Khan University Hospital), Karachi Pakistan. In this study various well-known equations for estimation of percentage body fat and fat mass in the western population have been validated for Pakistani children. Relatively smaller sample size is the basic limitation of this research output which warrants and provokes local researchers to do further studies in the future.

\section{INTRODUCTION}

Obesity is now being reported as the new world epidemic afflicting more than one billion adults globally. ${ }^{1}$ According to WHO reports a great number of children (22 million) are afflicted with obesity with a great proportion in the USA, however the developing nations are not to be spared. ${ }^{2}$ Analysis of the national health survey in Pakistan for adults reveals that lower body mass index (BMI) thresholds were suggested than those recommended in western population based on their association with outcome of chronic disease. ${ }^{3}$ The same situation exists in children. Retrospective analysis of data in Britain revealed that there was an increased risk of obesity in Afro Caribbean and Pakistani girls whereas Indian and Pakistani boys were found to be at higher risk of being overweight. ${ }^{4}$ In another study it was reported that the application of international standards did not provide a reliable result due to a significant difference in height at the same ages of children belonging to the Asian and African descent as compared with standard population who showed a greater proportion of 
central obesity. ${ }^{5}$ Based on these results emerged the concept of measuring body fat (BF) composition as standardisation of BMI as an obesity measurement index across different ethnicities which remains to be formulated.

$\mathrm{BF}$ composition is measured in children using dual energy X-ray absorptiometry (DEXA) as gold standard. Multiple validations of this technique with chemical composition, total body weighting and hydrodensitometry have been performed. ${ }^{6-8}$ Owing to its very small amount of radiation and short procedure time it is ideal for use in children. ${ }^{9}$

However it is not suitable for use in field work as it is not widely available and involves transportation of participants to tertiary care settings. Another method that has been validated and widely used in the west is prediction equations based on anthropometric indices such as skin fold (SF) thickness of the biceps, triceps and abdominal wall as well as waist circumference and waist hip ratios. The first equations that have been produced were initially derived by Slaughter et al. ${ }^{10}$ In a sample of 310 children and adults aged 8-29 years, prediction equations were cross validated against under body weighting using four compartment models, bone mineral studies and body water dilution. Special consideration for ethnicity and maturations was given. Multiple studies have tried to validate these equations in their population and on failing to do so derive their own equations. In a study by Goran et $a l^{11}$ they have previously cross-validated DEXA against pig carcasses in the paediatric weight range and then after adjusting fat mass (FM) values with coefficient they have derived equations in prepubescent children by identifying the best predictors for FM and deploying them in a prediction equation.

As a second part of the Goran study, Dezenberg et $a l^{12}$ also tried to validate the Slaughter and Goran equations in two different cohorts (the Alabama and the Vermont cohort) across multiple criteria and on failure to do so went ahead and formulated their own equations by identifying the best predictors. They also came up with the conclusion that although much work has been carried out larger cohorts with different ethnicities is needed to establish the authenticity of prediction equations for widespread use in field work. As availability of DEXA is limited to larger centres it is imperative to validate SF thickness equations for measurement of obesity in the general population.

The purpose of this study was to determine the correlation between DEXA and SF thickness equations for estimation of BF composition in secondary school children and validation of prediction equations (Slaughter, Goran and Dezenberg equations) against gold standard of DEXA by determining agreement and accuracy.

\section{MATERIALS AND METHODS}

This was a cross-sectional analytical study conducted in Nuclear Medicine section, Department of Radiology,
The Aga Khan University Hospital (AKUH), Karachi, Pakistan from January 2010 to May 2010.

The study population consisted of children enrolled from class 5 till matriculation in the academic year from August 2009 to May 2010 form two-community-based schools belonging to the middle class strata. After the initial approval from the principal and obtaining school consent, a briefing lecture was delivered to the children with diagrammatic presentation of the machine and SF callipers. Thereafter assent forms to be signed by the children themselves and consent forms to be signed by the parents were distributed among the children. Furthermore phone numbers were obtained from the school administration and parents called to further explain the procedures and obtain verbal consent as well. All children whose parents gave consent were enrolled and those children from whom consent could not be obtained were excluded.

The sampling strategy was convenient sampling where consecutive children were enrolled till completion of sample size. A sample size of 44 participants was needed to achieve $90 \%$ power to detect a change in slope from 0.0 under the null hypothesis to 0.45 under the alternative hypothesis when the SD of the Triceps SF is 5.90, the SD of FM by DEXA is 5.90, and the two-sided significance level is 0.05 . These values were obtained from a study performed in children aged $4-10$ years. ${ }^{13}$ However, since two schools were included, by considering a design effect of two, the required sample size was calculated as 88 participants.

Data collection was performed on a designed questionnaire for the study. It included the sociodemographic data of the subject and all independent variables. Training of the principal investigator (PI) and the data collector was conducted according to the National Health \& Nutrition Examination Survey (NHANES) manual. ${ }^{14}$ A senior radiologist trained the data collectors for identification of the anatomical surface landmarks where measurements of the SF were to be obtained namely the angle of the scapula, the iliac crest and the midpoint of the arm for measuring bicep and tricep SFs. Intraobserver and interobserver variability were assessed for 10 sets of reading and readings with a discrepancy for more than $0.4 \mathrm{~mm}$ were retaken and the procedure revised. Abdominal and hip circumference were measured using a measuring tape according to the described technique and a difference of more than $1 \mathrm{~cm}$ was considered unacceptable.

DEXA scan was performed on Hologic Discovery-A QDR series, USA. The parameters of the scan were alternating fan beam radiations of 140 and $100 \mathrm{kV}$ with a scan width of 26.4 inches and scan length of maximum 77 inches $(195 \mathrm{~cm})$. The participant was asked to change into a hospital gown and asked to lie straight on the table with hands by the side palms facing down away from the thighs and look at the ceiling to maintain head position. The body was positioned within the scan parameters marked on the table. The feet were rotated inwards so that the toes touched each other and taped so that the position was maintained. The method of 
performing the analysis of the estimation for per cent $\mathrm{BF}(\% \mathrm{BF})$ and total $\mathrm{FM}$ was conducted in the paediatric whole body scan mode for children up till 12 years of age. For children aged between 12 years onwards the adult scan mode was used for the calculation of BF composition parameters. Reliability between scans was achieved with phantom calibration.

The measure of FM and \%BF calculated by DEXA was received as a printout from the scanner and values were entered in the study pro forma. Prediction of the same parameters via preformed prediction equations (Slaughter, Goran and Dezenberg) using SF thickness and anthropometric measures were also made.

\section{Body measurements}

All body measurements were taken in accordance with the protocol described for anthropometric measurements in the NHANES-3. ${ }^{14}$ Body measurements were taken on the right side of the body.

Anthropometric measurements were taken using specially designed callipers (Holtain Callipers). The measurements included weight, triceps SF thickness and subscapular SF thickness.

Weight was measured using a Tanita TBF 305 BF analyser and weighing scales (Tanita UK Ltd, Yewsley, Middlesex, UK).

\section{Measuring SF thickness}

SF measurements were obtained in various areas of the body such as the anterior and posterior aspect of the upper arm corresponding to the bicep and tricep SF.

Sub scapular $S F$ was obtained by measuring the subcutaneous tissue beneath the shoulder blade.

Suprailiac $S F$ was obtained by measuring the fold above the pelvic bone laterally.

Abdominal $S F$ was measured just adjacent to the umbilicus.

Abdominal circumference was measured using a measuring tape at the level of the umbilicus.

Hip circumference was measured at the maximum curvature of the hips.

SF measurements were taken to the nearest $0.1 \mathrm{~mm}$. All SF measurements were carried out in duplicate (ie, twice by the same investigator) since these measures have the most variability. SF thickness was measured by Holtain Callipers. The procedure was thoroughly explained to the children and the use of the calliper was demonstrated on the child's palm.

The following prediction equations were used:

$F M$ is obtained as amount of fat calculated in kilograms predicted by the Dezenberg and Goran equations

Dezenberg equation:

$$
\begin{aligned}
\mathrm{FM}(\mathrm{kg})= & 0.342 \times \text { body mass }(\mathrm{kg})+0.256 \\
& \times \text { triceps SF }(\mathrm{mm})+0.837 \\
& \times \operatorname{sex}(1=\text { boy }, 2=\text { girl })-7.388
\end{aligned}
$$

Goran equation:

$$
\begin{aligned}
\mathrm{FM}(\mathrm{kg})= & 0.23(\text { sub scapular } \mathrm{SF})+0.18(\text { weight }) \\
& +0.13(\text { triceps } \mathrm{SF})-3.0
\end{aligned}
$$

$\% B F$ is obtained as a $\% \mathrm{BF}$ predicted by the Slaughter equation.

For boys

$$
\begin{aligned}
& \% \mathrm{BF}=1.21[\text { sum of triceps and subscapular } \mathrm{SF} \text { in } \mathrm{mm}] \\
& -0.008\left[9(\text { sum of triceps and subscapular } \mathrm{SF} \text { in } \mathrm{mm})^{2}\right] \\
& -1.7(\text { coefficient for Caucasian prepubescent in } \\
& \text { boys with sum of triceps and subscapular } \\
& \mathrm{SFs}<35 \mathrm{~mm}) ;
\end{aligned}
$$

If sum of triceps and subscapular $\mathrm{SFs}>35 \mathrm{~mm}$,

$\% \mathrm{BF}=0.783$ [sum of triceps and subscapular SFs $\mathrm{mm}$ ]

$$
-1.7 \text { in boys }
$$

For girls

$$
\begin{gathered}
\% \mathrm{BF}=1.33[\text { sum of triceps and subscapular } \mathrm{SFs}-\mathrm{mm}] \\
-0.013\left[(\text { sum of triceps and subscapular } \mathrm{SFs} \text { in } \mathrm{mm})^{2}\right] \\
+3.0(\text { coefficient for Caucasian girls }) \text { in girls with } \\
\text { sum of triceps and subscapular } \mathrm{SFs}<35 \mathrm{~mm}
\end{gathered}
$$

Or if sum of triceps and subscapular SFs $>35 \mathrm{~mm}$,

$$
\begin{aligned}
\% \mathrm{BF}= & 0.546[\text { sum of triceps and subscapular SFs in } \mathrm{mm}] \\
& +9.7 \text { in girls }
\end{aligned}
$$

Data for all the independent variables were collected by the PI and assisting technician in the Dexa room. Two readings were taken for height, weight, abdominal and hip circumference, triceps and subscapular and suprailiac SF thicknesses and the average measurement for both the readings was taken as the final reading. If a difference of more than $0.3 \mathrm{~mm}$ was recorded the readings were retaken. Calibration of the callipers was performed periodically according to the calibration block provided by the manufacturers. The stadiometer and weighing scale were also calibrated and checked for correct position of zero before each data set recording.

\section{Statistical analysis}

Descriptive statistics were calculated for the data with mean and SDs for all continuous variables. Proportions were described for categorical data such as gender and independent $\mathrm{t}$ test was applied to assess significant difference among gender. 
The next step of the analysis was to validate the equation for FM and \%BF described by Goran, Dezenberg and Slaughter. In order to do this initially correlations were established between estimated FM and \%BF calculated by DEXA and that predicted by using the three equations. On obtaining significant correlation of $>0.05$, precision and bias was calculated.

Accuracy was defined as the degree of closeness of predicted $\mathrm{FM}$ and $\% \mathrm{BF}$ obtained from the equations to their actual criterion value estimated by DEXA and would be considered significant if more than $90 \%$. This was carried out by obtaining the overall mean of FM and $\%$ BF by DEXA as well as the Dezenberg, Goran and Slaughter equations separately. Individual accuracies were then calculated by subtracting the predicted mean of $\% \mathrm{BF}$ and $\mathrm{FM}$ obtained from the equations from the mean value of FM and \%BF calculated by DEXA. The difference was then expressed as a percentage of the mean of the estimated DEXA value for the three equations.

Precision was defined as the variation between the predicted and estimated values of $\% \mathrm{BF}$ and $\mathrm{FM}$ within the data and was assessed as the average of the difference between FM and \%BF measured by DEXA and that predicted by the equations and plotting the mean of errors against 0 using paired samples $\mathrm{t}$ test.

Bland Altman plots were also generated for evaluation of agreement and bias. Based on the aforementioned criteria the equation for \%BF by Slaughter and for FM by Dezenberg and Slaughter were rendered valid or rejected. Post hoc regression analysis was also performed with the line of identity against predicted versus estimated FM and \%BF. A commercial Statistical Package for Social Sciences (SPSS V.17) was used for these measurements.

\section{RESULTS}

\section{Descriptive analysis and gender difference}

Ninety-nine $(\mathrm{n}=99)$ participants were registered with a mean age of $14 \pm 1.89$ years (min-max 9-19 years) with 54 male and 45 female participants. There was an evidence of overall increase in the adiposity of women as compared with men. All SF measures as well as fat composition variables were significantly higher in girls with $\mathrm{p}$ value $<0.05$. After assigning the binary variables it was observed that there was a difference of $3.57 \mathrm{~kg}$ FM present in excess in women as compared with men as calculated by DEXA ( $\mathrm{p}$ value $<0.0001$ ). Significant differences were also obtained for $\% \mathrm{BF}$ which was $6.2 \%$ more in women as compared with men ( $p$ value $<0.05$; table 1 ).

After obtaining baseline data, the equations were applied to the sample for prediction of FM by Dezenberg and Goran as well as $\% \mathrm{BF}$ by Slaughter. In the linear regression analysis strong correlations were obtained between the predicted values and the criterion values by DEXA with $\mathrm{p}$ value $<0.0001$ (table 2 ).
Table 1 Baseline demographic and measured values of studied participants

\begin{tabular}{lcc}
\hline Total participants: 99 & $\begin{array}{c}\text { Males=54 } \\
\text { mean (SD) }\end{array}$ & $\begin{array}{c}\text { Females=45 } \\
\text { mean (SD) }\end{array}$ \\
\hline Age (years) & $13.8(2.0)$ & $14.13(2.2)$ \\
Weight $(\mathrm{kg})^{*}$ & $41.7(12.5)$ & $43.6(8.2)$ \\
BMI $\left(\mathrm{kg} / \mathrm{m}^{2}\right)^{*}$ & $17.7(3.5)$ & $19.0(3.4)$ \\
SC-SF (mm) & $9.9(6.1)$ & $14.1(5.4)$ \\
T-SF $(\mathrm{mm})^{*}$ & $11.4(7.1)$ & $16.0(6.1)$ \\
FM by DZ-Eq & $8.9(5.4)$ & $12.7(4.1)$ \\
FM by G-Eq & $20.7(4.1)$ & $28.6(3.2)$ \\
\%BF BY SL-Eq & $10.7(9.3)$ & $13.3(5.1)$ \\
DEXA FM* & $8.3(5.6)$ & $10.2(3.2)$ \\
DEXA \%BF* & $19.1(7.6)$ & $29.6(5.1)$ \\
\hline
\end{tabular}

${ }^{*} p$ Value $<0.05$

BMI, body mass index, DZ-Eq, Dezenberg equation; FM, fat mass; G-Eq, Goran equation; \%BF, percentage body fat; SC-SF, subscapular skin fold; SL-Eq, Slaughter equation; T-SF, tricep SF.

\section{Validation of equations}

Overall accuracy

The overall accuracy for the Slaughter equation was $98.4 \%$ which was very high and Dezenberg equation had an overall accuracy of $90.3 \%$ which was just within the cut-off designed. Goran equation showed weak overall accuracy of $83 \%$ which did not fall within the cut-off defined.

\section{Variation/precision of equations}

No significant difference was obtained between the Slaughter equation predicting \% BF and that estimated by DEXA with a difference of $0.37 \mathrm{~kg}$ ( $\mathrm{p}$ value $=0.425$ ). However, significant differences for predicting FM were obtained between DEXA and Dezenberg. The equation underestimated the FM with a bias of $1.26 \mathrm{~kg}$ which was statistically significant ( $\mathrm{p}$ value $<0.0001$ ). While Goran equation overestimated the FM with a bias of $1.48 \mathrm{~kg}$ which was statistically significant with a p value of $<0.0001$.

\section{Calculating bias}

Limits of agreement were evaluated using Bland Altman analysis. The Slaughter equation revealed that more than $75 \%$ of the data was within the first SD. The Goran and Dezenberg equations revealed significant bias with

Table 2 Correlation coefficients calculated for prediction equations of DZ, G and SL for FM and \%BF

\begin{tabular}{lll}
\hline Equations & $\mathbf{R}^{\mathbf{2}}$ & SEE \\
\hline DZ-FM & 0.8 & 2.45 \\
G-FM & 0.86 & 2.06 \\
SL-\%BF & 0.76 & 3.73 \\
\hline
\end{tabular}

DZ-FM, Dezenberg fat mass; G-FM: Goran fat mass; SL \%BF: Slaughter percentage body fat; SEE: standard error of estimate. All equations showed good correlations with estimated FM and percentage BF using DEXA showing significant $p$ values of $<0.0001$. 
overestimation and underestimation of FM although the limits of agreement were narrow (figure 1A, B).

Thus in view of the aforementioned criteria the Slaughter equation fulfilled all the criteria for predicting $\% \mathrm{BF}$ accurately as the overall accuracy is high with minimal variation which is not statistically significant and showing good precision with $\% \mathrm{BF}$ measured by
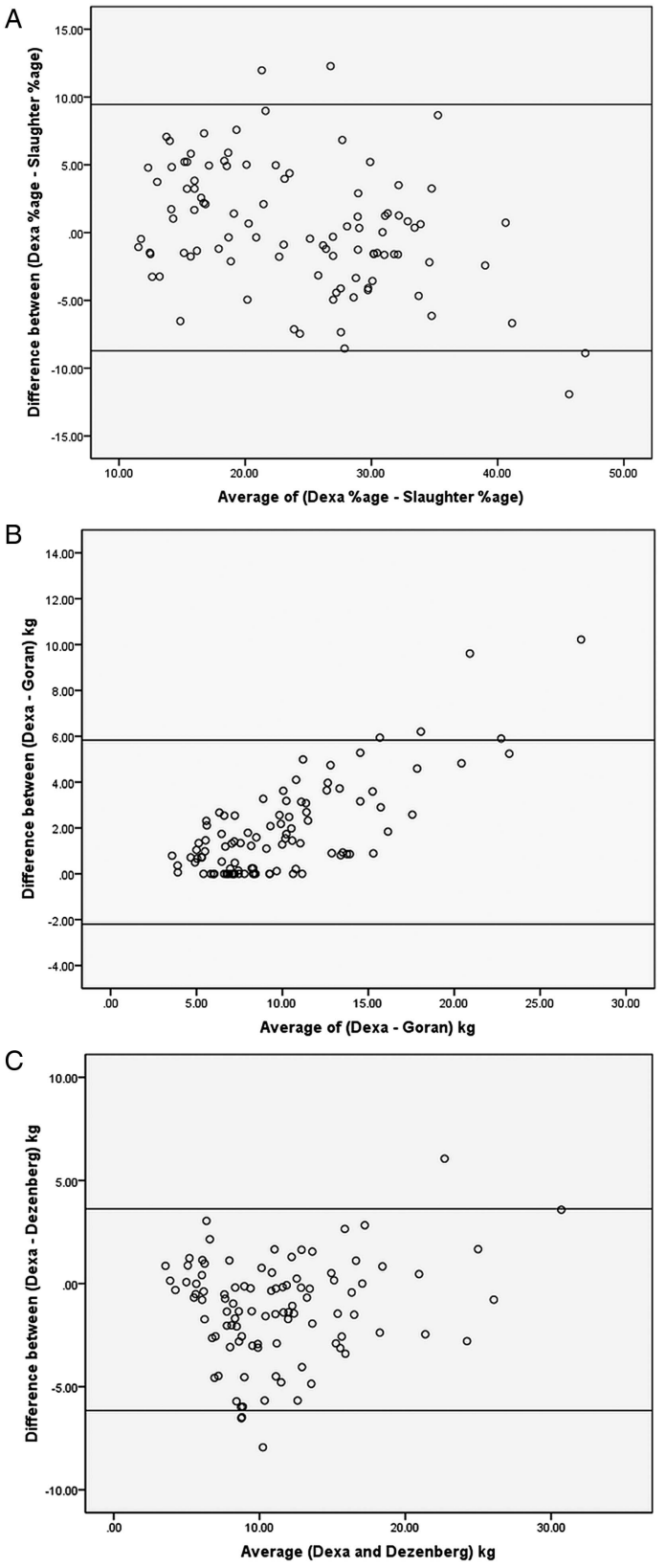

Figure 1 (A) Bland Altman plot showing uniform distribution between percentage body fat calculated by dual energy X-ray absorptiometry (DEXA) and Slaughter equation. Although limits of agreement wide more than $75 \%$ of sample is between $5 \%$ variation; $(B)$ significant overestimation of fat mass between DEXA and Goran equation with almost the entire sample above the 0 levels; $(C)$ significant underestimation of fat mass with more than $60 \%$ of the sample lying below the 0 level in the Dezenberg equation.
DEXA. Furthermore more than $75 \%$ of the readings were within $5 \%$ of the estimated DEXA values.

The Dezenberg and Goran equations had a significant variation in prediction of FM which was statistically significant with low level of accuracy of the Goran equation. A summary of the results is shown in table 3 .

Post hoc regression analysis revealed that the Goran as well as the Dezenberg equations did not reveal an intercept significantly different from zero (figure 2A, B). The Slaughter equation did not reveal an intercept significantly different from zero against estimated FM (figure 2D). However, the intercept was significantly different from zero when it was assessed against estimated $\% \mathrm{BF}$ (figure $2 \mathrm{C}$ ).

\section{DISCUSSION}

The onset of obesity in the paediatric population has shown early precedence of atherosclerotic changes and diabetes mellitus with the onset of metabolic syndrome thus rendering obesity as a major health concern. Thus with this background we set out to conduct a study for the measurement of obesity in our paediatric population. A new technique of predicting $\mathrm{BF}$ composition is by prediction equations (Salughter, ${ }^{10}$ Goran $^{11}$ and Dezenberg $^{12}$ equations) which have been developed for the western world. We attempted to validate these equations to predict $\mathrm{BF}$ composition in our paediatric population which comprised of FM and \% BF using DEXA as the gold standard. In this study only the Slaughter equation was validated for predicting $\% \mathrm{BF}$ with a good correlation and high accuracy $(98.4 \%)$. No significant bias was seen among the predicted and estimated method for measuring $\% \mathrm{BF}$. These equations have been validated in different studies and used widely. In a study carried out by Janz et $a l^{15}$ in 122 participants of prepubescent and postpubescent children ranging from 8 to 17 years very high intraclass correlations $(0.98-0.99)$ and high validity correlations of (0.79-0.99) were achieved. In another study conducted in Zaragoza, Spain carried out on 237 adolescents it was found that the Slaughter equations had the narrowest limits of agreement as compared with the other equations and did not show statistically significant bias. ${ }^{16}$ Our results have been similar with the equation showing validity across all criteria.

In the study by Goran $e t a l$, after failing to validate the Slaughter equation they derived an equation for their own sample. It was reported that all SFs showed higher correlations with $\mathrm{FM}$ rather than $\% \mathrm{BF}$ so an equation for the prediction of FM was generated. Another method of calculating fat composition was also deployed in this study using bioelectrical impedance analysis. They found the variables of triceps, subscapular and weight significantly correlating. The equation was further cross validated on one-third of the sample according to the criteria of Lohman and colleagues which consisted of assessing the difference between the 
Table 3 Validation criteria for prediction of $\%$ body fat and fat mass

\begin{tabular}{lccc}
\hline & Slaughter & Goran & Dezenberg \\
\hline Correlation & 0.76 & 0.8 & 0.86 \\
Accuracy & 98.4 & 90.3 & 83.7 \\
Precision & $0.37(p=0.4)$ & $-1.26(p<0.0001)$ & $1.48(p<0.0001)$ \\
\hline
\end{tabular}

According to all three criteria the Slaughter equation showed consistency good correlation, very high accuracy and good precision using paired $t$ test.

predicted and estimated FM as well as minimal increase of the standard error of estimate. Only the $\mathrm{R}^{2}$ was reported 0.88 .
This equation was then further cross validated in the study by Dezenberg. In his study after initially failing to validate the Goran and Slaughter equation, a prediction
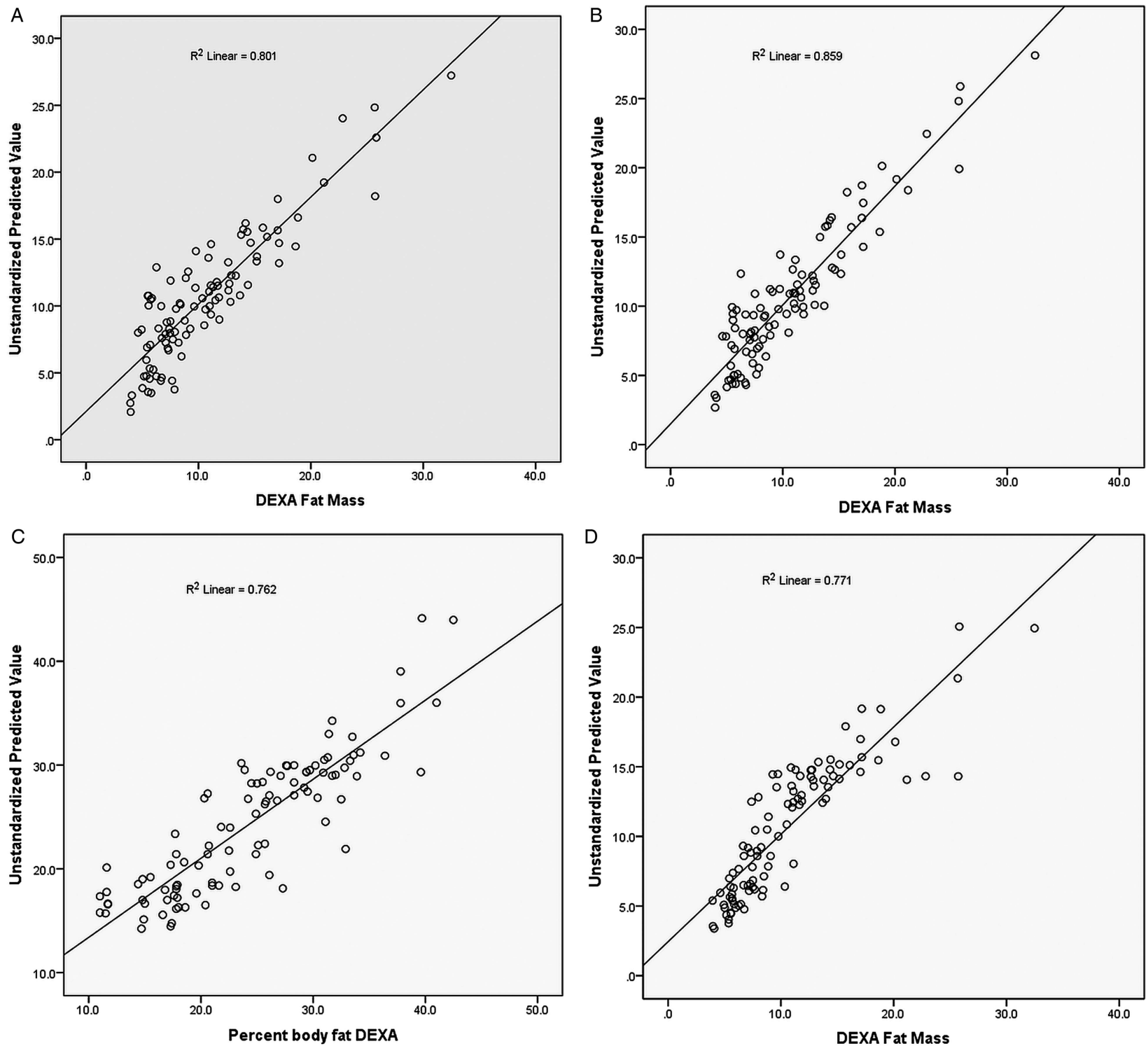

Figure 2 (A and B) Regression analysis with line of identity showing the intercept at an angle of $45^{\circ}$ not significantly different from zero in the Dezenberg and Goran equations. (C) Reveals the regression analysis with line of identity between Slaughter percentage body fat (\%BF) and estimated \%BF dual energy X-ray absorptiometry (DEXA) with intercept significantly different from zero. (D) Reveals intercept not significantly different from zero between the Slaughter equation for \%BF and fat mass estimated by DEXA. 
equation was formulated across a sample of different ethnic cohorts consisting of African-American as well as Caucasian population. The predictors considered significant were weight; triceps SF, gender, ethnicity and abdominal SF. However, since we were not evaluating ethnicity, the equation adopted in this study consisted only of weight, triceps SF and gender predictors. A significant point of concern in this study was the fact that regression analysis was performed between $\% \mathrm{BF}$ as predicted by Slaughter against FM as predicted by DEXA. Since both variables were in different units the inability to validate the equations appeared inevitable. In our study adopting the approach of Dezenberg et al we achieved good correlation with the intercept not significantly different from zero with Slaughter equations predicting $\% \mathrm{BF}$ and $\mathrm{FM}$ in kilograms estimated by DEXA (figure 2D) however the regression analysis between predicted $\% \mathrm{BF}$ and that estimated with DEXA shows an intercept significantly different from zero (figure 2C). Despite this as multiple validation criteria were applied and the Slaughter equation maintained robustness across all of them it can be used with some considerations of maturity specificity and ethnicity in our population.

Our results were similar to the results by Eisenmann who evaluated a number of equations along with bioelectrical impedance analysis. In his study he found that the Slaughter equations consisting of triceps and subscapular SF were showing better limits of agreement and reduced bias where only one of the Slaughter equations was adopted. Significant differences were assessed between the methods for evaluating BF composition by DEXA and SF equations, bioelectrical impedance.

A few issues are worthy of mention here. These results could be explained by the application of coefficients that were derived for the western population. Therefore determining coefficients for the predictors used in the Dezenberg equation and deriving a prediction equation that is sample specific could possibly yield better results.

Another reason for the inability to validate the DZ equation might be that our sample consisted of prepubescent as well as postpubescent children. The application of maturity specific coefficients by performing the Tanner staging might have different results as these were conducted on children who were prepubescent. Furthermore data regarding the ethnic origin and sociodemographic status was also not applied. However, all children were living in the same town going to community centre schools with a middle class status.

The Goran equation also was established on a cohort of children whose mean age was much lower than that of our sample. Furthermore gender was not accounted for in the equation we used whereas in our population significant differences were found between boys and girls for FM as well as all SFs.

Very few studies have been carried out regionally in the South Asian population. In a study conducted in Sri Lanka, in 282 children ages ranging from 5 to 15 years, were tested for predicted \%BF using multiple equations as well as Slaughter equation. ${ }^{17}$ Although the bias calculated (-11.6 to 5.8) was not significant but the limits of agreement were high with significant underestimation of $\% \mathrm{BF}$ rendering the equation invalid. An explanation for these results could be the criterion method that was used which was isotope dilution. No results have been stated for validation against DEXA. In our study, bias was not significant and more than $75 \%$ of the samples were between a $5 \%$ variation as compared with DEXA (figure 1C). In 2010 a study was conducted in Hong Kong where children aged 9-19 were recruited and SF thickness were validated with subsequent formation of new equations. ${ }^{18}$ However, again the criterion used was air displacement plethysmography with only a subset validation with DEXA. They found significant difference between \%BF estimated by the Slaughter equation although the absolute value was only of $1.52 \%$. This was negated by our study which could be explained by the criterion method as being different and a significant difference in ethnicity. To the best of our acknowledgement this is the first study conducted in Pakistani paediatric population to determine the correlation and validation of $\mathrm{SF}$ thickness equations for estimation of $\mathrm{BF}$ composition using DEXA as the gold standard.

\section{LIMITATIONS}

Owing to the addition of two schools the effect of institution was added as a result of which the formation and validation of FM equation for our population could not be assessed as the control group and validation group had significant differences between them.

As the age range was wide, different levels of maturity needed to be assessed by the Tanner staging.

Data for ethnic origin and sociodemographics were not held in consideration.

Furthermore, the cut-off for accuracy, to be deemed significant was $90 \%$ which was an arbitrary figure and not used previously. However, the Slaughter equation revealed a figure of $98.4 \%$ which is very high.

In post hoc analysis regression analysis was performed for checking the line of identity in measured versus predicted FM and \%BF. Although the Dezenberg and Goran equations revealed higher correlations with intercept not statistically different from 0 they were showing significant differences in FM prediction. While the Slaughter equation was showing an intercept different from 0 it was fulfilling all other criteria and we believe that if studies with larger sample size and accounting for ethnicity and maturity specific coefficients are performed it will stand its robustness.

\section{CONCLUSIONS}

We conclude that the Slaughter equation for estimating $\% \mathrm{BF}$ showed reasonably strong validation with DEXA. However, for interchangeable use with DEXA further studies with larger sample sizes and maturity considerations need to be conducted. 
However, for estimation of FM, the previously formulated equations by Goran and Dezenberg revealed significant difference in our population. We do recommend further cross-validation studies for developing and validation of SF equation specific to Pakistani paediatric population.

Acknowledgements The authors would like to acknowledge the department of community health sciences for their support in carrying out the logistics of the study. The authors would also acknowledge the efforts of Dr Nadeem Ahmad ex-chairperson for his support in the project.

Contributors All authors have substantially contributed to the conception and design of the study, acquisition of the data, analysis and interpretation of the data and preparation of the manuscript.

Funding This work was funded by the University research council of Aga Khan University Hospital.

Competing interests None.

Patient consent Obtained.

Ethics approval The study was approved by Aga Khan Medical University Ethical Review Committee, Karachi, Pakistan

Provenance and peer review Not commissioned; externally peer reviewed.

Data sharing statement No additional data are available.

Open Access This is an Open Access article distributed in accordance with the Creative Commons Attribution Non Commercial (CC BY-NC 4.0) license, which permits others to distribute, remix, adapt, build upon this work noncommercially, and license their derivative works on different terms, provided the original work is properly cited and the use is non-commercial. See: http:// creativecommons.org/licenses/by-nc/4.0/

\section{REFERENCES}

1. Puska P, Nishida C. Obesity and overweight. Global strategy on diet, physical activity and health. World Health Organization, 2003. http:// www.who.int/dietphysicalactivity/publications/facts/obesity/en/index. $\mathrm{html}$

2. Young-Hyman D, Schlundt DG, Herman L, et al. Evaluation of the insulin resistance syndrome in 5- to 10-year-old overweight/obese African-American children. Diabetes Care 2001;24:1359-64.
3. Yusuf S, Hawken S, Ounpuu S, et al. Effect of potentially modifiable risk factors associated with myocardial infarction in 52 countries (the INTERHEART study): case-control study. Lancet 2004;364:937-52.

4. Strauss $\mathrm{R}$, Pollack $\mathrm{H}$. Epidemic increase in childhood overweight, 1986-1998. JAMA 2001;286:2845-8.

5. Cole T, Bellizzi M, Flegal K, et al. Establishing a standard definition for child overweight and obesity worldwide: international survey. $B M J$ 2000;320:1240.

6. Wang ZM, Pierson RN Jr, Heymsfield SB. The five-level model: a new approach to organizing body-composition research. Am Soc Nutr 1992:19-28.

7. Johansson AG, Forslund A, SjÖdin A, et al. Determination of body composition-a comparison of dual-energy $\mathrm{x}$-ray absorptiometry and hydrodensitometry. Am J Clin Nutr 1993:57:323-26.

8. Pintauro S, Nagy TR, Duthie C, et al. Cross-calibration of fat and lean measurements by dual energy $\mathrm{x}$-ray absorptiometry to pig carcass analysis in the pediatric body weight range. Am J Clin Nutr 1996;63:293-99.

9. Ellis J, Shypailo R, Pratt $\mathrm{J}$, et al. Accuracy of dual energy x-ray absorptiometry in children for body composition measurements. Am $J$ Clin Nutr 1994;60:660-65.

10. Slaughter MH, Lohman TG, Boileau RA, et al. Skinfold equations for estimation of body fatness in children and youth. Hum Biol 1988;60:709-23.

11. Goran M, Driscoll $P$, Johnson R, et al. Cross-calibration of body-composition techniques against dual-energy $\mathrm{X}$-ray absorptiometry in young children. Am J Clin Nutr 1996;63:299-305.

12. Dezenberg CV, Nagy TR, Gower BA, et al. Predicting body composition from anthropometry in preadolescent children. Int $J$ Obes 1999;23:253-9.

13. Eisenmann J, Heelan K, Welk G. Assessing body composition among 3- to 8-year-old children: anthropometry, BIA, and DXA. Obesity Res 2004:12:1633-40.

14. National health and nutrition examination survey III. Body measurements (anthropometry). Rockville, MD 20850: Westat, Inc. 1650 Research Boulevard. http://www.cdc.gov/nchs/data/nhanes/ nhanes3/cdrom/.../ANTHRO.PDF

15. Janz KF, Nielsen DH, Cassady SL, et al. Cross-validation of the Slaughter skinfold equations for children and adolescents. Med Sci Sports Exerc 1993;25:1070

16. Rodriguez G, Moreno LA, Blay MG, et al. Body fat measurement in adolescents: comparison of skinfold thickness equations with dual-energy X-ray absorptiometry. Eur J Clin Nutr 2005;59:1158-66.

17. Wickramasinghe VP, Lamabadusuriay SP, Cleghorn GJ, et al. Use of skin-fold thickness in Sri Lankan children: comparison of several prediction equations. Indian J Pediatr 2008;75:1237-42.

18. Midorikawa T, Ohta M, Hikihara Y, et al. Predicting total fat mass from skinfold thicknesses in Japanese prepubertal children: a cross-sectional and longitudinal validation. Asia Pac J Clin Nutr 2011;20:426-31. 